\title{
Análise preliminar de riscos na atividade de acabamento e revestimento externo de um edifício
}

\author{
Preliminary risk analysis of the finishing and external covering procedures of a building \\ Mairla Germana Pitombeira Viana',Cacilda Sousa Alves², Carlos Enrique de Medeiros Jerônimo³ \\ 'Especialista , Universidade Potiguar, Natal - RN, Brasil \\ ${ }^{2}$ Mestre em Engenharia de Petróleo e Gás. Universidade Potiguar, Natal - RN, Brasil \\ ${ }^{3}$ Doutor. Engenheiro de Processamento de Petroleo da Petrobras. Universidade Potiguar, Natal - RN, Brasil
}

\begin{abstract}
Resumo
O presente estudo buscou identificar os principais riscos/perigos envolvidos na fase de acabamento e revestimento de um edifício. Para tanto, realizou-se uma pesquisa exploratório/qualitativa que possibilitou o levantamento dos riscos/perigos a que estão submetidos os colaboradores envolvidos nessa atividade. Os dados foram coletados e analisados utilizando- se a técnica de Análise Preliminar de Risco (APR), que consiste em um estudo antecipado e detalhado de todas as fases do trabalho a fim de detectar os possíveis problemas que poderão acontecer durante a execução de uma determinada tarefa. Com os resultados obtidos detectou-se os possíveis acidentes e problemas relacionados à execução desta atividade o que levou à proposição de algumas medidas de controle com o intuito de neutralizar os riscos existentes.
\end{abstract}

Palavras-chave: Segurança no trabalho. Riscos. Análise preliminar de riscos. Construção civil.

\begin{abstract}
The present study focus on the identification of the main risks/dangerous situations involved on the finishing and covering stages of a building. Therefore, an exploratory/qualitative research was performed, which made possible the assessment of the risks/dangerous situations to which the collaborators involved on such activity are exposed to. The data were collected and analyzed under the Risk Preliminary Analysis (RPA) technique, which consists of an anticipated study and detailmentof all the stages of the work in order to detect possible issues that may appear during the execution of a task. The results of such analysis made possible to anticipate probable accidents and problems related to this activity, and orienting the proposition control measures aimed on neutralizing the present risks.
\end{abstract}

Keywords: Work safety. Risks. Preliminary Risk Analysis. Construction. 


\section{INTRODUÇÃO}

A Construção Civil é uma área que embora represente um importante setor da economia (10\% do PIB da U.E., 24\% do mercado mundial, 1350000 empresas na Europa e 12,5\% da população ativa empregada na U.E.), infelizmente, é também reconhecida pelo seu elevado índice de sinistralidade. Este elevado índice está inevitavelmente associado às especificidades que caracterizam o setor e a vários fatores como os que se enumeram a seguir:

- Sobreposição de tarefas (no espaço e no tempo):

- Pluralidade e diversidade de intervenientes e empresas em ação simultânea;

- Desconhecimento do território do estaleiro e da evolução da sua edificação;

- Presença de elementos físicos no espaço envolvente do estaleiro (linhas elétricas, condutas de água e gás, circulação de pessoas e veículos...);

- Reduzido ou nulo espaço de crescimento dos estaleiros;

- Freqüentes situações de trabalho em altura ou abaixo do solo;

- Forte circulação interna de pessoas, materiais e equipamentos;

- Complexidade e diversidade de armazenamento dos materiais e de parqueamento dos equipamentos;

- Distanciamento da projetista face à execução do projeto e dos seus executantes;

- Dispersão da responsabilidade por diversas instâncias;

A Indústria da Construção Civil (ICC) marca a sua importância, não só como meio de absorção de mão de obra, mas também pela execução de obras de infraestrutura que permitem escoar a produção (tanto de insumos como de bens finais) através de rodovias, ferrovias, linhas de transmissão de energia elétrica, etc.

A ICC possui grande destaque entre os diversos ramos da cadeia produtiva nacional. Pertence ao grupo dos setores que mais empregam no país, sendo de relevante importância para a economia.

Por outro lado, é um dos principais responsáveis pela geração de prejuízos ao Brasil, devido aos Acidentes de Trabalho (AT) gerados, segundo Instituto Brasileiro de Geografia e Estatística (IBGE) e Ministério da Previdência e Assistência Social (DRAGONI, 2005).

O trabalho na construção civil, assim como em outras atividades, é realizado em locais de trabalho que pela própria natureza da atividade desenvolvida podem comprometer a saúde e segurança do trabalhador em curto, médio e longo prazo, provocando lesões imediatas, doenças ou a morte.

A Segurança do Trabalho é um tema de grande relevância, não apenas para a construção civil, mas também para os mais diferentes ramos de atividades laborativas.

A ICC mantém elevados índices de Acidentes de Trabalho e apresenta uma das piores condições de segurança do trabalho, em nível mundial. A baixa qualificação, a elevada rotatividade e o reduzido investimento por parte das empresas em treinamento e desenvolvimento costumam ser característicos dessa indústria, justificando tais afirmativas (ANDRADE; BASTOS, 1999). Desta forma, em qualquer tipo de atividade laboral, torna-se imprescindível a necessidade de investigar o ambiente de trabalho para conhecer os riscos a que estão expostos os colaboradores. De acordo com Pacheco Jr. (2000), a política de segurança, medicina e saúde ocupacional deve estar presente nas organizações e empresas de construção civil, a responsabilidade distribuída em todos os níveis e incorporada a toda sua hierarquia.

Segundo Cardella (2010, p.37), a Segurança no Trabalho é "o conjunto de ações exercidas com o intuito de reduzir danos e perdas provocados por agentes agressivos. ", ou seja, a preocupação está na redução de riscos e de suas fontes.

Segurança do Trabalho é o conjunto de medidas de ordem técnica, educacional, médica e psicológicas utilizadas para prevenir acidentes, quer eliminando a condição insegura do ambiente quer instruindo ou convencendo as pessoas da implantação das práticas preventivas. (CHIAVENATO, 2010 p. 477).

A Segurança e saúde no trabalho podem ser caracterizadas como medidas preventivas contra acidentes de trabalho e doenças ocupacionais.

Para Araujo (2006), as organizações devem garantir que suas operações e atividades sejam realizadas de maneira segura e saudável para os seus empregados, atendendo aos requisitos legais de saúde e segurança, regidos pela Consolidação das Leis Trabalhistas (CLT) e Normas Regulamentadoras que tratam de Segurança e Saúde ocupacional. Assim, o sistema de gestão atua no comprometimento 
e atendimento aos requisitos legais e regulatórios, podendo trazer inúmeros benefícios tanto do ponto de vista financeiro quanto do ponto de vista motivacional.

Segundo Bergamini (1997), a melhoria da segurança, saúde e meio ambiente de trabalho, além de aumentar a produtividade, diminui o custo do produto final, pois diminui as interrupções no processo, absenteísmo e acidentes e/ou doenças ocupacionais.

Nos diversos locais de trabalho, existem inúmeras situações de risco, passiveis de provocar acidentes. Dessa forma, uma análise, um mapeamento e um gerenciamento completo desses riscos, tornam-se um elemento imprescindível para a prevenção de acidentes.

Na implementação de Sistemas de Gestão de Segurança e Saúde no Trabalho, a Gestão de Riscos constitui o aspecto essencial a ter em conta na política de prevenção integrada definida pelas empresas. De um modo simples e claro, segundo GONÇALVEZ (2000) a Gestão de Riscos pode ser definida como a aplicação sistemática de estratégias, procedimentos e práticas com o objetivo de identificar os perigos e analisar, avaliar e controlar os riscos de acidentes.

Dentre as formas de desenvolver o gerenciamento de riscos, segundo Camacho (2005) e CETESB (2000), a técnica de análise preliminar de riscos (APR) permite quantificar a magnitude dos riscos existentes. E, como conseqüência, hierarquizar de modo racional a prioridade da sua eliminação ou correção (MARTINS; NATACCI, 2009).

Para TAVARES (2004) a análise preliminar de riscos (APR) consiste no estudo realizado durante a fase de concepção ou no desenvolvimento de um sistema, com o fim de se determinarem os riscos que poderão estar presentes na fase operacional.

$\mathrm{Na}$ construção civil, em especial nas etapas de acabamento e revestimento, praticamente não são encontrados estudos que direcionem as atividades aos seus riscos inerentes. Sendo assim, este trabalho consiste em avaliar os riscos existentes nessa fase da construção civil. Sendo desenvolvida uma proposta de medidas mitigadoras para cada risco encontrado com a finalidade de eliminar os agentes causais ou diminuir as conseqüências e assim contribua para a melhoria da saúde e segurança dos trabalhadores.

\section{OBJETIVOS}

Este trabalho tem como objetivo realizar o levantamento dos riscos/perigos envolvidos na atividade de acabamento e revestimento externo de um edifício, utilizando a ferramenta Análise Preliminar de Riscos (APR).

\section{JUSTIFICATIVA}

Sem dúvida alguma, a construção civil é uma atividade que gera receita e emprego na sociedade. Porém é uma das atividades que mais acarreta acidentes com seus colaboradores, então discutir sobre os riscos provenientes dessa atividade se faz necessário. Devido à existência dos riscos dentro dos procedimentos dos serviços executados na construção civil, há a necessidade de identificá-los e criar condições e procedimentos que aliem segurança do trabalhador e qualidade da obra.

Observando-se a necessidade de analisar os riscos aos trabalhadores envolvidos na atividade de execução de formas e tendo como premissa que a Engenharia de Segurança do Trabalho atua na prevenção de acidentes é que se optou por fazer o presente trabalho.

Propor-se-á neste trabalho, um estudo sobre os riscos inerentes ao trabalho na fase de acabamento e revestimento externo, utilizando-se a técnica da Análise Preliminar de Riscos (APR).

\section{METODOLOGIA}

\section{1 Área de estudo}

O presente trabalho foi desenvolvido em um edifício residencial localizado na cidade de Mossoró- $\mathrm{RN}$, e que se encontrava na fase de acabamento e revestimento externo. 


\subsection{Levantamento de dados}

O estudo constitui-se de uma pesquisa aplicada, pois objetiva produzir conhecimentos em segurança e saúde no trabalho para aplicação no ramo da construção civil. Do ponto de vista dos objetivos, trata-se de um estudo exploratório-descritivo, o qual visa descrever a problemática em discussão, buscando caracterizar o objeto de estudo.

O trabalho consiste em avaliar os riscos nos serviços de acabamento e revestimento de um edifício, bem como, propor medidas adequadas que contribuam para a melhoria da segurança e saúde de seus trabalhadores.

Do ponto de vista dos procedimentos técnicos, o estudo caracteriza-se como pesquisa bibliográfica, por sua elaboração a partir do levantamento e analise de material já publicado, em artigos científicos, livros, relatórios técnicos, etc. (SILVA; MENEZES, 2001), e como estudo de caso devido à utilização de dados de campo.

A estrutura da pesquisa consiste em: formulação do problema, englobando a justificativa do estudo; a determinação dos objetivos; a contextualização da problemática e definição da metodologia; realização do levantamento teórico, que orienta a caracterização do objeto de estudo; as definições e conceitos a serem utilizados em analise e correntes de pensamentos que norteiam a hipótese da pesquisa; levantamento de dados em campo e a discussão sobre as melhorias que possam acarretar.

Os dados coletados, em campo, foram organizados e utilizados para elaboração da Planilha de Analise Preliminar de Riscos (APR).

Esse estudo foi realizado com base num levantamento exploratório qualitativo que possibilitou descrever e analisar os riscos. Os dados foram coletados e analisados utilizando-se como técnicas de trabalho em campo e de interpretação das informações coletadas, respectivamente, a observação e a analise preliminar de riscos.

\subsection{Análise de risco}

A Análise Preliminar de Riscos (APR) é definida como um estudo realizado na fase de concepção ou desenvolvimento de um novo sistema ou processo, com o objetivo de determinar os riscos que podem estar presentes na fase operacional do processo (DE CICCO; FANTAZZINI, 2003).

A APR é aplicada para uma análise inicial qualitativa, desenvolvida na fase de projeto e de processo, produto ou sistema, com especial importância para investigação de novos sistemas de alta inovação ou pouco conhecidos, isto é, quando a experiência em riscos na operação é deficiente. Além das características básicas de análise inicial, torna-se útil também como uma ferramenta de revisão geral de segurança em sistemas já operacionais, mostrando aspectos que poderiam passar despercebidos (FARIA, 2011). a saber:

Segundo Sherique (2011, p.535), a elaboração de uma APR passa por algumas etapas básicas,

a) Revisão de problemas conhecidos: A busca por analogias ou similaridades com outros sistemas;

b) Revisão da missão a que se destina: Atentar aos objetivos, exigências de desempenho, principais funções e procedimentos, estabelecer os limites de atuação e delimitar o sistema;

c) Determinação dos riscos principais: Apontar os riscos com potencialidade para causar lesões diretas imediatas, perda de função, danos a equipamentos e perda de materiais;

d) Revisão dos meios de eliminação ou controle de riscos: Investigar os meios possíveis de eliminação e controle de riscos, para estabelecer as melhores opções compatíveis com as exigências do sistema;

e) Analisar os métodos de restrição de danos: Encontrar métodos possíveis e eficientes para a limitação dos danos gerados pela perda de controle sobre os riscos;

f) Indicação de quem levará a sério as ações corretivas e/ou preventivas: Indicar responsáveis pela execução de ações preventivas e/ou corretivas, designando também, para cada unidade, as atividades a desenvolver.

Os resultados da APR são registrados convenientemente numa planilha, conforme ilustrado no Quadro 1. Que, para cada etapa do processo, mostra os perigos identificados, as causas, o modo de detecção, efeitos potenciais, categorias de freqüência, severidade e risco, as medidas corretivas e/ ou preventivas e o número do cenário (Amorim, 2010). 
Quadro 1 - Planilha de Análise Preliminar de Riscos.

\begin{tabular}{|c|c|c|c|c|c|c|c|c|c|}
\hline \multicolumn{10}{|c|}{ Análise Preliminar de Riscos (APR) } \\
\hline \multirow{2}{*}{$\begin{array}{l}\text { Etapa do } \\
\text { processo }\end{array}$} & \multirow{2}{*}{ Perigo } & \multirow{2}{*}{$\begin{array}{c}\text { Causa } \\
\text { (s) }\end{array}$} & \multirow{2}{*}{$\begin{array}{l}\text { Modos de } \\
\text { Deteç̧ão }\end{array}$} & \multirow{2}{*}{ Efeitos } & \multicolumn{3}{|c|}{ Categorias } & \multirow{2}{*}{ Recomendações/Obs. } & \multirow{2}{*}{$\begin{array}{l}\text { № do } \\
\text { Cenário }\end{array}$} \\
\hline & & & & & Frequência & Severidade & Risco & & \\
\hline & & & & & & & & & \\
\hline & & & & & & & & & \\
\hline & & & & & & & & & \\
\hline
\end{tabular}

Fonte: Autores.

A realização da análise propriamente dita é feita através do preenchimento de uma planilha de APR para cada etapa do processo. A planilha adotada para a realização da APR, mostrada no Quadro 1 , contém nove colunas, as quais devem ser preenchidas conforme as descrições a seguir:

O processo de execução da APR consiste em dividir o processo em estudo em etapas que ficará na coluna ETAPA DO PROCESSO, identificar os perigos, eventos iniciadores em potencial, e outros eventos capazes de gerar conseqüências indesejáveis para cada etapa do processo que ficará na coluna PERIGO, identificar as causas de cada perigo que ficará na coluna CAUSAS, modo de detecção, como esse risco foi detectado que ficará na coluna MODO DE DETECÇÃO. Os possíveis efeitos danosos de cada perigo identificado serão listados na coluna EFEITOS, no âmbito da APR, um cenário de acidente é definido como o conjunto formado pelo perigo identificado, suas causas e cada um dos seus efeitos que ficará na coluna CATEGORIAS DE FREQUENCIA. Deste modo, classificaram-se cada cenário de acidente em uma categoria de freqüência, a qual fornece uma indicação qualitativa da freqüência esperada de ocorrência para cada cenário identificado, conforme a Tabela 1 (AMORIM, 2010).

Tabela 1 - Categorias de Freqüência dos cenários da APR.

\begin{tabular}{|c|c|l|}
\hline Categoria & Denominação & \multicolumn{1}{c|}{ Descrição } \\
\hline A & Extremamente Remota & Extremamente improvável de ocorrer durante a vida útil da instalação \\
\hline B & Remota & Não deve ocorrer durante a vida útil da instalação \\
\hline C & Improvável & Pouco provável que ocorra durante a vida útil da instalação \\
\hline D & Provável & Esperado ocorrer pelo menos uma vez durante a vida útil da instalação \\
\hline E & Frequente & Esperado ocorrer várias vezes durante a vida útil da instalação \\
\hline
\end{tabular}

Fonte: Adaptado de AMORIM, 2010.

Também de acordo com a metodologia de APR adotada neste trabalho, os cenários de acidentes foram classificados em categorias de severidade, as quais fornecem uma indicação qualitativa do grau de severidade das conseqüências de cada um dos cenários identificados.

As categorias de severidade utilizadas no presente trabalho estão discriminadas na Tabela 2 (AMORIM, 2010).

Tabela 2 - Categorias de Severidade dos cenários da APR.

\begin{tabular}{|c|c|l|}
\hline Categoria & Denominação & \multicolumn{1}{c|}{ Descrição/Características } \\
\hline I & Desprezivel & $\begin{array}{l}\text { Não ocorrem lesões ou mortes de funcionários, de terceiros (não funcionários) e/ou de } \\
\text { pessoas extramuros (indústrias e comunidade); o máximo que pode ocorrer são casos } \\
\text { de primeiros socorros ou tratamento médico menor. }\end{array}$ \\
\hline II & Marginal & Lesões leves em funcionários, terceiros e/ou em pessoas extramuros; \\
\hline III & Crítica & $\begin{array}{l}\text { Lesões de gravidade moderada em funcionários, em terceiros e/ou em pessoas extra- } \\
\text { muros (probabilidade remota de morte de funcionários e/ou de terceiros); exige ações } \\
\text { corretivas imediatas para evitar seu desdobramento em catástrofe. }\end{array}$ \\
\hline IV & Catastrófica & $\begin{array}{l}\text { Provoca mortes ou lesões graves em várias pessoas (em funcionários e/ou em pessoas } \\
\text { extramuros); }\end{array}$ \\
\hline
\end{tabular}

Fonte Adaptado de AMORIM, 2010. 
Combinando-se as categorias de freqüência com as de severidade obtêm-se a Matriz de Riscos, conforme o tabela 3 , a qual fornece uma indicação qualitativa do nível de risco de cada cenário identificado na análise que ficará na coluna CATEGORIA DE RISCO. O resultado dessa matriz permite visualizar os cenários de acidente de maior impacto para a segurança do processo. (AMORIM, 2010).

Tabela 3 - Matriz de Classificação de Riscos usada na APR.

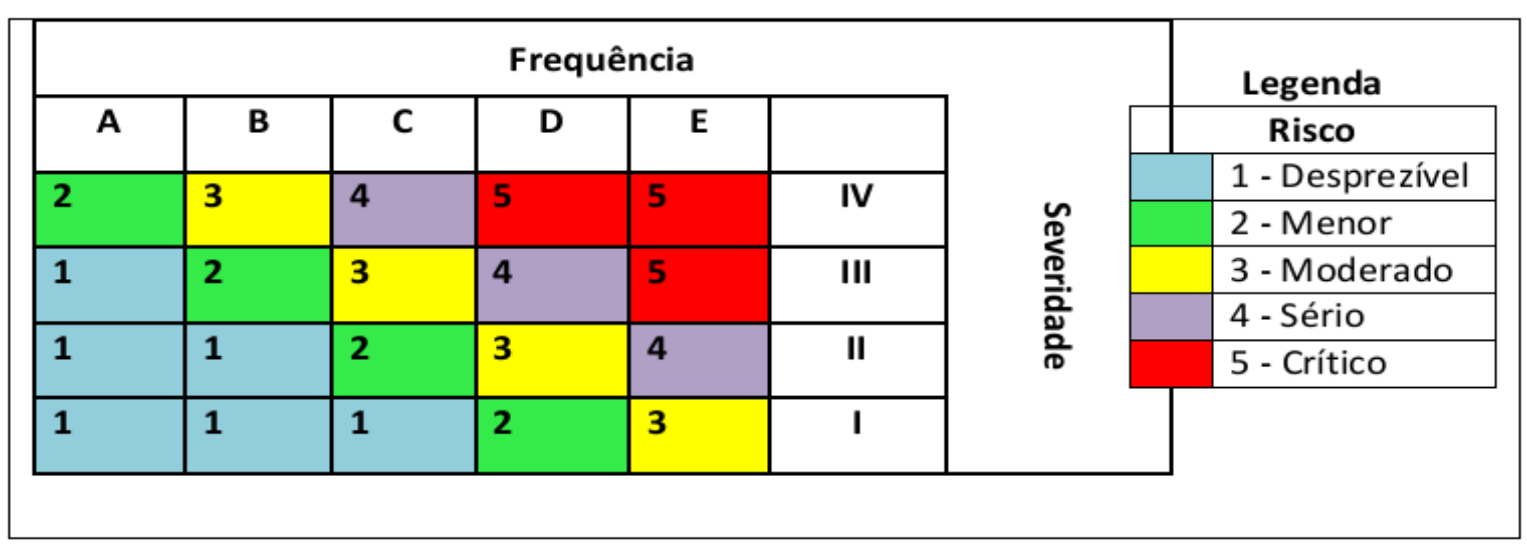

Fonte: Camacho (2005) e Amorim (2010).

As medidas que devem ser tomadas para diminuir a freqüência ou severidade do acidente ou quaisquer observações pertinentes ao cenário de acidente em estudo ficaram na coluna RECOMENDAÇÕES E OBSERVAÇÔES. Na coluna NÚMERO DO CENÁRIO, ficará um numero de identificação do cenário de acidente, para facilitar a consulta a qualquer cenário de acidente.

\section{RESULTADOS E DISCUSSÕES}

Para qualificar o espaço amostral utilizado para levantamento da matriz de riscos, foram descritas cada uma das etapas que compõe a fase de acabamento e revestimento.

\subsection{Acabamento e revestimento}

A área em estudo trata- se de um edifício residencial, que se encontra na fase de acabamento e revestimento externo. Primeiramente é feito o serviço de regularização de superfície por meio de lixamento das superfícies a serem acabadas, posteriormente é feito o revestimento cerâmico ou pastilhado. E por ultimo, a limpeza da fachada.

O lixamento de superfícies tem como objetivo eliminar lombadas e desníveis na superfície, facilitando as etapas posteriores. O lixamento deve ser feito de forma a não deixar a superfície lisa ou áspera demasiadamente. Após o lixamento das superfícies, e feito a colocação do revestimento cerâmico.

O revestimento cerâmico é colocado por meio de argamassa colante, a argamassa colante é espalhada sobre a superfície com auxilio de desempenadeira, logo após é colocado a placa cerâmica. Depois de 3 dias é feito o rejuntamento. Posteriormente é feita a limpeza, que é a operação final e tem a finalidade de eliminar resíduos de argamassa e outros materiais usados no processo de assentamento.

\subsection{Análise preliminar de risco}

Na concepção de Ayres; Correa (2001) é considerado um risco ambiental o agente físico, químico, biológico, ergonômico e/ou de acidentes/mecânicos que possam, de acordo com a natureza, trazer ou ocasionar danos à saúde do trabalhador nos ambientes de trabalho. Sherique (2004) complementa esta definição, afirmando que para que esses sejam considerados fatores de riscos ambientais os mesmos precisam estar presentes no ambiente de trabalho, porém, em uma determinada concentração, intensidade e/ou tempo de exposição.

Este trabalho buscou identificar os riscos desta atividade em especial na fase de acabamento e revestimento. Os riscos encontrados foram: 
Tabela 4 - Matriz de Classificação de Riscos obtida pela aplicação da APR.

\begin{tabular}{|c|c|c|c|c|c|c|c|}
\hline & \multicolumn{7}{|c|}{$\begin{array}{l}\text { Análise Preliminar de Perigos (APP) } \\
\text { Acabamento e revestimento }\end{array}$} \\
\hline \multirow{2}{*}{$\begin{array}{l}\text { Etapa do } \\
\text { processo }\end{array}$} & \multirow[t]{2}{*}{ Perigo } & \multirow[t]{2}{*}{ Causas } & \multirow[t]{2}{*}{ Consequências } & \multicolumn{3}{|c|}{ CATEGORIA } & \multirow[t]{2}{*}{ Recomendações } \\
\hline & & & & Frequência & Severidade & Risco & \\
\hline \multirow{3}{*}{ 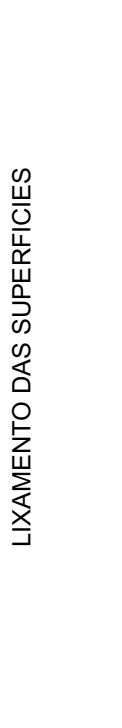 } & 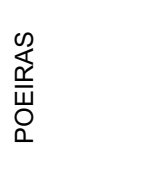 & $\begin{array}{c}\text { Inalação de } \\
\text { poeiras devido } \\
\text { ao lixamento } \\
\text { das } \\
\text { superfícies. }\end{array}$ & $\begin{array}{l}\text { Dermatites, } \\
\text { conjuntivite e } \\
\text { problemas } \\
\text { respiratórios. }\end{array}$ & E & II & 4 & $\begin{array}{l}\text { Utilizar máscaras } \\
\text { contra poeiras, luvas } \\
\text { impermeáveis. }\end{array}$ \\
\hline & 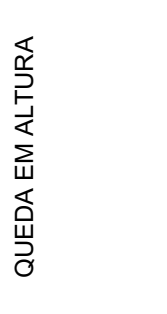 & $\begin{array}{l}\text { Não uso do } \\
\text { cinto de } \\
\text { segurança; } \\
\text { falta de } \\
\text { manutenção } \\
\text { do } \\
\text { equipamento; } \\
\quad \text { falta de } \\
\text { treinamento; }\end{array}$ & $\begin{array}{c}\text { Fraturas, } \\
\text { escoriações e até } \\
\text { óbito. }\end{array}$ & D & II & 3 & $\begin{array}{l}\text { Utilizar bancadas } \\
\text { adequadas, cinto de } \\
\text { segurança tipo pára- } \\
\text { quedista com } \\
\text { talabarte }\end{array}$ \\
\hline & 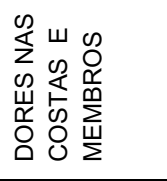 & $\begin{array}{c}\text { Postura } \\
\text { inadequada e } \\
\text { movimentos } \\
\text { repetitivos. }\end{array}$ & $\begin{array}{l}\text { Lesão na coluna } \\
\text { cervical, baixa } \\
\text { produtividade, } \\
\text { LER, etc. }\end{array}$ & D & II & 3 & $\begin{array}{l}\text { Ginástica laboral, } \\
\text { treinamento sobre } \\
\text { postura adequada, } \\
\text { etc. }\end{array}$ \\
\hline \multirow{4}{*}{ 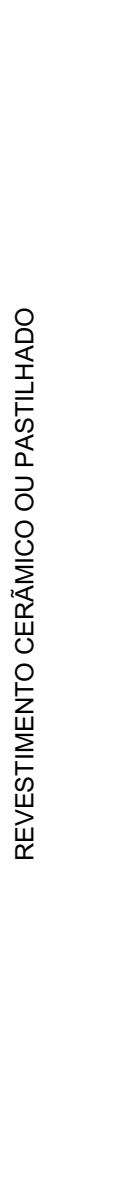 } & 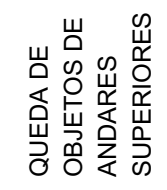 & $\begin{array}{c}\text { Desprendimen } \\
\text { to de matérias; } \\
\text { queda de } \\
\text { ferramentas; }\end{array}$ & Danos físicos & D & II & 3 & $\begin{array}{l}\text { Uso de tela } \\
\text { fachadeira; }\end{array}$ \\
\hline & 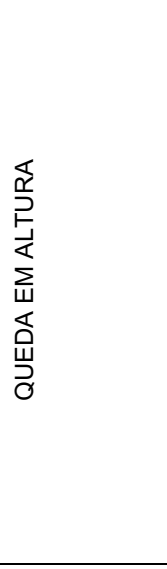 & $\begin{array}{l}\text { Não uso do } \\
\text { cinto de } \\
\text { segurança; } \\
\text { falta de } \\
\text { manutenção } \\
\text { do } \\
\text { equipamento; } \\
\text { falta de } \\
\text { treinamento; }\end{array}$ & $\begin{array}{c}\text { Fraturas, } \\
\text { escoriações e até } \\
\text { óbito. }\end{array}$ & D & II & 3 & $\begin{array}{c}\text {-proteção contra } \\
\text { quedas de alturas; } \\
\text { - revisão periódica, } \\
\text { vistoriando o estado } \\
\text { de conservação dos } \\
\text { andaimes; } \\
\text { - respeitar as cargas } \\
\text { mínimas previstas } \\
\text { em norma NR18; } \\
\text { - prender os cabos } \\
\text { dos andaimes em } \\
\text { peças estruturais; } \\
\text { - permitir somente a } \\
\text { manipulação dos } \\
\text { balancins por } \\
\text { trabalhadores } \\
\text { especializados; }\end{array}$ \\
\hline & 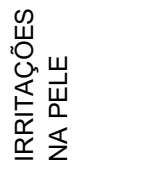 & $\begin{array}{l}\text { Irritações na } \\
\text { pele devido ao } \\
\text { trabalho com } \\
\text { cimento. }\end{array}$ & Dermatoses & E & II & 4 & $\begin{array}{l}\text { Uso de luvas } \\
\text { impermeáveis. }\end{array}$ \\
\hline & 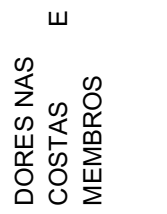 & $\begin{array}{c}\text { Postura } \\
\text { inadequada e } \\
\text { movimentos } \\
\text { repetitivos. }\end{array}$ & $\begin{array}{l}\text { Lesão na coluna } \\
\text { cervical, baixa } \\
\text { produtividade, } \\
\text { LER, etc. }\end{array}$ & D & II & 3 & $\begin{array}{l}\text { Ginástica laboral, } \\
\text { treinamento sobre } \\
\text { postura adequada, } \\
\text { etc. }\end{array}$ \\
\hline
\end{tabular}


Tabela 4 - Continuação...

\begin{tabular}{|c|c|c|c|c|c|c|c|}
\hline \multicolumn{8}{|c|}{$\begin{array}{l}\text { Análise Preliminar de Perigos (APP) } \\
\text { Acabamento e revestimento }\end{array}$} \\
\hline \multirow{2}{*}{$\begin{array}{l}\text { Etapa do } \\
\text { processo }\end{array}$} & \multirow[t]{2}{*}{ Perigo } & \multirow[t]{2}{*}{ Causas } & \multirow[t]{2}{*}{ Consequências } & \multicolumn{3}{|c|}{ CATEGORIA } & \multirow[t]{2}{*}{ Recomendações } \\
\hline & & & & Frequência & Severidade & Risco & \\
\hline \multirow{3}{*}{ 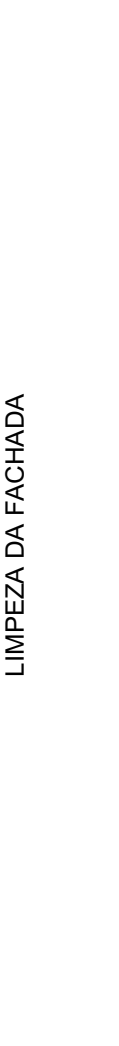 } & 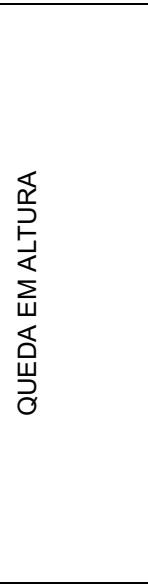 & $\begin{array}{l}\text { Não uso do } \\
\text { cinto de } \\
\text { segurança; } \\
\text { falta de } \\
\text { manutenção } \\
\quad \text { do } \\
\text { equipamento; } \\
\text { falta de } \\
\text { treinamento; }\end{array}$ & $\begin{array}{l}\text { Fraturas, } \\
\text { escoriaçōes e até } \\
\text { óbito. }\end{array}$ & D & II & 3 & $\begin{array}{c}\text {-proteção contra } \\
\text { quedas de alturas; } \\
\text { - revisãa periódica, } \\
\text { vistoriando o estado } \\
\text { de conservação dos } \\
\text { andaimes; } \\
\text { - respeitar as cargas } \\
\text { mínimas previstas } \\
\text { em norma NR18; } \\
\text { - prender os cabos } \\
\text { dos andaimes em } \\
\text { peças estruturais; } \\
\text { - permitir somente a } \\
\text { manipulação dos } \\
\text { balancins por } \\
\text { trabalhadores } \\
\text { especializados; }\end{array}$ \\
\hline & 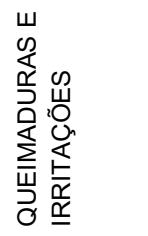 & $\begin{array}{l}\text { Utilização de } \\
\text { produtos } \\
\text { químicos. }\end{array}$ & $\begin{array}{c}\text { Queimaduras e } \\
\text { irritações na pela. }\end{array}$ & D & II & 3 & $\begin{array}{l}\text { Utilização de luvas } \\
\text { impermeáveis e } \\
\text { protetor facial. }\end{array}$ \\
\hline & 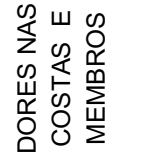 & $\begin{array}{l}\text { Postura } \\
\text { inadequada e } \\
\text { movimentos } \\
\text { repetitivos. }\end{array}$ & $\begin{array}{l}\text { Lesão na coluna } \\
\text { cervical, baixa } \\
\text { produtividade, } \\
\text { LER, etc. }\end{array}$ & D & II & 3 & $\begin{array}{l}\text { Ginástica laboral, } \\
\text { treinamento sobre } \\
\text { postura adequada, } \\
\text { etc. }\end{array}$ \\
\hline
\end{tabular}

Risco químico, que segundo a Norma Regulamentadora 9 são causadas por agentes químicos que são substâncias, compostos ou produtos que possam penetrar no organismo pela via respiratória, nas formas de poeiras, fumos, névoas, neblinas, gases ou vapores, ou que, pela natureza da atividade de exposição, possam ter contato ou ser absorvidos pelo organismo através da pele ou por ingestão.

Riscos de acidentes, que são todos os fatores que colocam em perigo o trabalhador ou afetam sua integridade física ou moral. É qualquer fator que coloque o trabalhador em situação vulnerável que possa afetar sua integridade, e seu bem estar físico e psíquico. Como por exemplo, máquinas e equipamentos sem proteção ou defeituosos, probabilidade de incêndio ou explosão, arranjo físico inadequado, armazenamento inadequado, etc.

Risco ergonômico, que está associado a qualquer fator que possa interferir nas características psicofisiológicas do trabalhador, causando desconforto ou afetando sua saúde. Como por exemplo, levantamento de peso, ritmo excessivo de trabalho, postura inadequada, falta de iluminação ou ventilação, etc. Aplicando-se os conceitos acima a metodologia da APR, os cenários de acidente foram devidamente classificados quanto às categorias de freqüência, severidade e de risco, conforme se observa na Tabela 4.

Nos resultados encontrados após aplicação da APR, identificou-se risco sério (categoria 4), nas etapas de "Lixamento de superfícies", poeiras e "Revestimento cerâmico", irritações na pele. Identificou-se também risco moderado (categoria 3), na etapa de "Lixamento de superfícies", queda de altura, queda de objetos e dores nas costas e membros. Na etapa de "Revestimento cerâmico", queda de altura e dores nas costas e membros, e na etapa de "Limpeza da fachada", queda de altura, queimaduras e irritações e dores nas costas e membros. 
Os riscos encontrados e enquadrados na categoria 4 (riscos sério), requerem maiores cuidados, devendo-se assim implantar medidas preventivas eficientes que minimizam e/ou neutralizam os riscos identificados, como por exemplo, treinamento dos trabalhadores.

$\mathrm{E}$ os riscos enquadrados na categoria 3 (risco moderado), apesar de terem sido enquadrados numa categoria inferior aos outros riscos deverão ser observados e neutralizados com a implementação das medidas corretivas e/ou preventivas sugeridas.

\section{CONCLUSÃO}

Como se pode observar, na construção civil, em especial a fase de acabamento e revestimento externo, expões os seus colaboradores a riscos tais como: quedas, irritações, queimaduras, poeiras e posturas inadequadas.

A técnica de análise preliminar de risco mostrou-se eficaz, pois o resultado da APR permitiu visualizar os eventos de maior impacto, para a segurança do processo de acabamento e revestimento externo.

O levantamento dos riscos envolvidos nas atividades de acabamento e revestimento externo evidenciou por meio da interpretação da Matriz de Risco que os riscos identificados nestas atividades ocorrem ocasionalmente e não causam grandes danos ao colaborador, à empresa e ao meio ambiente. Entretanto, como contribuição à saúde e bem estar dos colaboradores foram indicadas algumas medidas mitigadoras e de prevenção aos riscos a tais atividades, tais como: fornecimento e uso adequado do EPI, treinamentos, exames periódicos, dentre outras.

\section{REFERÊNCIAS}

AMORIM, E. L. C. de. Ferramentas de Análise de Risco. Apostila do curso de Engenharia Ambiental da Universidade Federal de Alagoas, CTEC, Alagoas: 2010. Disponível em: <http://pt.scribd.com/doc/71505557/ Apostila-de-ferramentas-de-analise-de-risco >. Acesso em: 08 jul. 2012.

ANDRADE, R. S., BASTOS, A.B. Qualificação entre empregados da construção civil - uma avaliação, pelos empregados, de uma experiência organizacional, 1999. Disponível em: <http://www.ufba.br/conpsi/ conpsi1999/P183.html>. Acesso em: 20 abr. 2008.

ARAUJO, R. P. Sistemas de Gestão em Segurança e Saúde no Trabalho: Uma Ferramenta Organizacional. Joinville: Monografia Apresentada à Universidade de Santa Catarina para obtenção de título de especialista em Segurança do Trabalho, UDESC 2006.

AYRES, D. de O.; CORRÊA, J. A. P. Manual de Prevenção de Acidentes do Trabalho. São Paulo, Editora ATLAS, 2001.

BERGAMINI, C. W. Motivação nas organizações. 4. ed. São Paulo: Atlas, 1997.

CAMACHO, E. N. Uma Proposta de Metodologia para Análise Quantitativa de Riscos Ambientais. (2004). Tese - Programa de Pós-graduação de Engenharia, Universidade Federal do Rio de Janeiro, 2004.

CARDELLA, B.. Segurança no trabalho e prevenção de acidentes: uma abordagem holística: segurança integrada à missão organizacional com produtividade, qualidade, preservação ambiental e desenvolvimento de pessoas. São Paulo: Atlas, 2010.

CETESB. Manual de orientação para elaboração de estudos de análise de riscos. 2000.

CHIAVENATO, Idalberto. Gestão de Pessoas. 3. ed. rev. Atual. Rio de Janeiro: Elsevier, 2010. 
DE CICCO, Francesco; FANTAZZINI, Mário Luiz. Tecnologias consagradas de gestão de riscos. 2 ed. São Paulo: Risk Tecnologia, 2003.

DRAGONI, José Fausto. Segurança, Saúde e Meio Ambiente em Obras: diretrizes voltadas à gestão eficaz de segurança patrimonial e meio ambiente em obras de pequeno, médio e grande porte. São Paulo: Editora LTr, 2005.

FARIA, Maila Teixeira. Gerência de riscos: apostila do curso de especialização em engenharia de segurança do trabalho. Curitiba: UTFPR, 2011.

GONÇALVEZ, Edwar Abreu. Segurança e Medicina do Trabalho em 1.200 Perguntas e Respostas. $3^{\text {a }}$ Ed. São Paulo, Editora LTR, 2000.

MARTINS, M. R.; NATACCI, F. B. Metodologia para análise preliminar de riscos de um navio de transporte de gás natural comprimido. In: Congresso Pan-Americano de Engenharia Naval, Transporte Marítimo e Engenharia Portuária, 2009, Montevideo. XXI Congreso Panamericano de Ingeniería Naval, 2009. p. 1-15.

PACHECO JR, Waldemar. Gestão da Segurança e Higiene do Trabalho: Contexto Estratégico, Análise Ambiental e Avaliação das Estratégias. SãoPaulo: Atlas, 2000.

SHERIQUE, Jaques. Aprenda como fazer. 7 ed. São Paulo: LTr2011.

SHERIQUE, Jaques. Aprenda como fazer: PRRA, PCMAT E MRA. São Paulo: LTR, 2004.

SILVA, E. L.; MENEZES, E. M. Metodologia da pesquisa e elaboração de dissertação. 3 ed. Rev. Atual. Florianópolis: Laboratório de Ensino a Distancia da UFSC, 2001.

TAVARES, José da Cunha. Noções de Prevenção e controle de perdas em segurança do trabalho. São Paulo: Senac, 2004. 